\title{
Spinal injuries in sports in the UK
}

\author{
J. R. Silver MB BS FRCP(Ed)(Lond) \\ National Spinal Injuries Centre, Stoke Mandeville Hospital, Aylesbury, Bucks, UK
}

\begin{abstract}
An analysis was made of 150 rugby, trampolining, gymnastics and horse-riding injuries between 1952 and 1985, resulting in severe spinal injury. The individual analyses of the separate sports had been published previously. There are common factors to all these sports. Of those injured 121 had cervical injuries often as a result of participation in sport by young impetuous people, and causes included: inadequate supervision; motivation to attempt tasks beyond their abilities; a mismatch between the abilities of the performer and the task attempted.
\end{abstract}

Keywords: Spinal injuries, comparisons, common factors

About 15 million people in the UK participate regularly in some form of sporting activity. There are consequently many sports related injuries, mostly soft tissue injuries, but it is recognized that only about half will report to the doctor. The most catastrophic injury is spinal injury. With the improved methods of treatment patients with spinal injuries can expect to have a near normal life expectancy but the cost in human and financial terms is high. There are about 300 spinal injuries per year in the UK, and the congregation of these patients at spinal centres allows detailed analysis of the clinical manifestations and mechanics of injury. Previous papers $^{1-5}$ describe spinal injuries caused by individual sports but this paper synthesizes the factors common to sports as diverse as horse-riding and rugby.

It is important to determine if changes in the method of executing the sport, changes in attitude of the participants and administrators, or changes in the laws governing those sports will prevent spinal injury.

\section{Subjects and methods}

Histories of patients were obtained in large part from the records of the Liverpool Spinal Injuries Centre and the National Spinal Injuries Centre (NSIC), and also from Oswestry, the Midlands Spinal Centre and the Welsh Spinal Centre.

The subjects were identified from patient notes, and a questionnaire was developed with the help of

Address for correspondence: Dr J. R. Silver, National Spinal Injuries Centre (NSIC), Stoke Mandeville Hospital, Mandeville Road, Aylesbury, Bucks HP21 8AL, UK

(C) 1993 Butterworth-Heinemann Ltd 0306-3674/93/020115-06 experts in the respective field. The agreed questionnaire was used prospectively for new patients and was sent retrospectively to other patients. Further information was obtained from witnesses or from subsequent court hearings. Information obtained included age, sex, level of cord and vertebral injury, fitness, method of causation of injury, any illegality involved and equipment failure.

\section{Results}

\section{Incidence}

A comparison was made between the admissions during 1951-1968 and 1984-1988 (Table 1). The proportion of road traffic accidents and falls has remained constant. There has been a dramatic increase in criminal injuries. Sporting injuries have increased and there has been a change in the representation of the different sports.

\section{Level of injury}

Of 150 patients, 121 had injuries of the cervical spine.

\section{Anatomical factors and mechanics of injury}

The cervical spine is particularly vulnerable to injury. It is mobile and the likelihood of damage is enhanced by the disparity in the movements of the unsupported skull on the cervical spine. The skull may be likened to a heavy ball on the end of a chain. The force created by its movement will fall on the two vulnerable junctions: that of the skull and cervical spine and that of the mobile cervical spine and fixed thoracic spine. The danger of dislocation is increased by the minimally oblique alignment of the facets, which present little resistance to dislocation.

\section{Flexion}

A force exerted through the crown of the head is transmitted through the skull to the cervical vertebrae, and results in crushing of the vertebrae and extrusion of vertebral body and disc material posteriorly into the cervical cord. Alternatively dislocation may occur without any fracture of the vertebrae. Roaf ${ }^{6}$, using cadaveric spines, was unable to produce dislocation without fracture by hyperflexion alone and found that some rotation must occur. Bauze and Ardran ${ }^{7}$ showed that when the vertex is fixed (for example, being locked on the ground, a common 
Table 1. Acute trauma admissions to the National Spinal Injuries Centre

\begin{tabular}{|c|c|c|c|c|c|c|c|c|c|c|}
\hline \multirow[b]{2}{*}{ Period } & \multirow[b]{2}{*}{$R T A$} & \multirow[b]{2}{*}{ Falls } & \multirow[b]{2}{*}{ Criminal } & \multirow[b]{2}{*}{$\begin{array}{l}\text { Sport } \\
\text { total }\end{array}$} & \multicolumn{5}{|c|}{ Main causes of sport accidents in UK } & \multirow[b]{2}{*}{$\begin{array}{c}\text { Overall } \\
\text { total }\end{array}$} \\
\hline & & & & & Diving & Riding & Rugby & Gymnastics & Other & \\
\hline $\begin{array}{l}1951-1968 \\
1984-1988\end{array}$ & $\begin{array}{l}340(57.8) \\
181(52.7)\end{array}$ & $\begin{array}{r}175(29.8) \\
86(25.1)\end{array}$ & $\begin{array}{r}2(0.3) \\
16(4.7)\end{array}$ & $\begin{array}{l}71(12.1) \\
60(17.5)\end{array}$ & $\begin{array}{l}42(7.1) \\
24(7.0)\end{array}$ & $\begin{array}{c}8(1.4) \\
16(4.7)\end{array}$ & $\begin{array}{c}5(0.85) \\
14(4.1)\end{array}$ & $\begin{array}{c}5(0.85) \\
-\end{array}$ & $\begin{array}{c}11(1.9) \\
6 \text { (Skiing) } \\
(1.7)\end{array}$ & $\begin{array}{l}588(100) \\
343(100)\end{array}$ \\
\hline
\end{tabular}

Numbers in parentheses are percentages; RTA, road traffic accidents

occurrence in rugby) far less force is required to dislocate the vertebrae and that dislocation can occur without fracture.

\section{Extension}

The anterior-posterior diameter of the spinal canal is reduced during extension of the cervical spine so that the spinal cord is compressed between the discs and vertebral bodies anteriorly and the lamina and ligaments posteriorly; the cord can thus be injured without overt fracture or dislocation - the so-called 'extension' injury.

A blow to the neck as in a short arm tackle in rugby is rare but can result in transient spasm of the vessel without any bony injury.

The striking feature is that the majority of these injuries involve the cervical spine and cord (Table 2).

\section{Temporal changes in causes of spinal injury}

In earlier years gymnastics and trampolining injuries were common, with rugby injuries uncommon and horse-riding accidents rare. Latterly, horse-riding, snow sports and rugby injuries have increased.

\section{Distribution of injuries by sex}

There is a preponderance of spinal injuries in sportsmen, admittedly few women play rugby, but in the sports where women participate fully, i.e. gymnastics and trampolining, there is a far smaller number $(8 / 46)$. Injuries to women predominate in horse-riding $(7 / 3)$.

\section{Age related injury}

These accidents occur in younger age groups, horse-riding being the exception with one or two elderly participants.

\section{Causes}

\section{Lack of supervision}

Gymnastics/trampolining

Six of the 16 trampoline and 12 of 38 gymnastic accidents occurred in an unsupervised gymnasium (Figure 1).

\section{Rugby}

One player was injured when someone jumped on the back of his unguarded neck while he was resting on the ground; one drunk player fell downstairs at 04.00 hours while on tour; and one was tipped over someone's back in an exercise in which players' arms were linked.

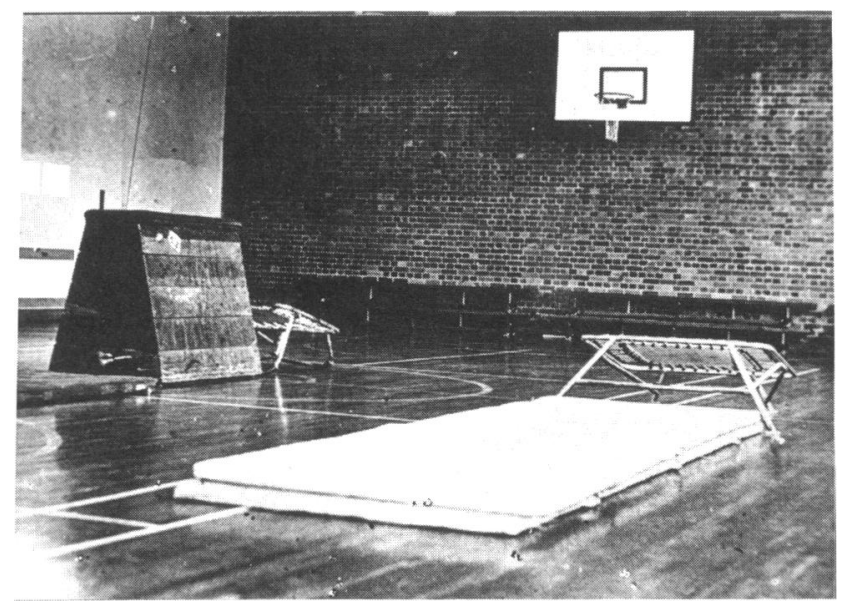

Figure 1. Scene of an actual accident. Note the old fashioned trampette and the lack of crash mats either side of the landing area

Table 2. Analyses of 121 cervical sports injuries and their distribution

\begin{tabular}{|c|c|c|c|c|c|c|c|}
\hline Sport & $\begin{array}{l}\text { Date of } \\
\text { paper }\end{array}$ & $\begin{array}{l}\text { Period of } \\
\text { study }\end{array}$ & $\begin{array}{c}\text { No. of } \\
\text { patients }\end{array}$ & $\begin{array}{l}\text { Male/ } \\
\text { female }\end{array}$ & $\begin{array}{l}\text { Age } \\
\text { range }\end{array}$ & $\begin{array}{l}\text { No. of cervical } \\
\text { injuries }\end{array}$ & $\begin{array}{l}\text { Other } \\
\text { lesions }\end{array}$ \\
\hline Rugby' & 1984 & $1952-1982$ & 67 & $67 / 0$ & $15-40$ & 47 & 20 \\
\hline Rugby $^{2}$ & 1988 & 1983-1987 & 19 & $19 / 0$ & $13-43$ & 18 & 1 \\
\hline Trampolining ${ }^{4}$ & 1986 & $1963-1978$ & 16 & $13 / 3$ & $10-43$ & 15 & 1 \\
\hline Gymnastics $^{3}$ & 1986 & 1954-1984 & 38 & $33 / 5$ & $12-54$ & 35 & 3 \\
\hline Horse-riding 5 & 1991 & $1976-1985$ & 10 & $3 / 7$ & $10-70$ & 6 & 4 \\
\hline Total & & & 150 & $135 / 15$ & & 121 & \\
\hline
\end{tabular}




\section{Mismatch between strength and skill}

\section{Gymnastics/trampolining}

Gymnastic and trampolining accidents were multifacetal. In virtually all cases the participants were attempting a programme beyond their abilities.

\section{Rugby}

In rugby the clearest discrepancy of strength and skill is in the front rows of the scrum. On four occasions there was a discrepancy of skills, and on seven occasions schoolboys were playing with adults - they were unable to match them in strength, and on three occasions the scrum collapsed. On two further occasions participants were overmatched, inexpert, or playing in unfamiliar positions. This was particularly marked in those matches played at school where there was only a small pool of players (Figure 2).

\section{Horse-riding}

All the injuries sustained in horse-riding were multifacetal. The experience of seven of the riders was inadequate for the capabilities of the horse.

\section{Competitive sports}

\section{Gymnastics/trampolining}

Injuries sustained by an international trampolinist participating in the Royal Tournament were probably caused as a result of the stress of competition.

\section{Rugby}

Of the 67 games in which injuries were sustained, three were of first class standard, 34 were club games, 12 were school team games, four were other school games, and three were practice games. Sixteen injured schoolboys were school team players, four were not, and most injuries occurred in competitive games, with games against the 'old boys' being particularly dangerous.

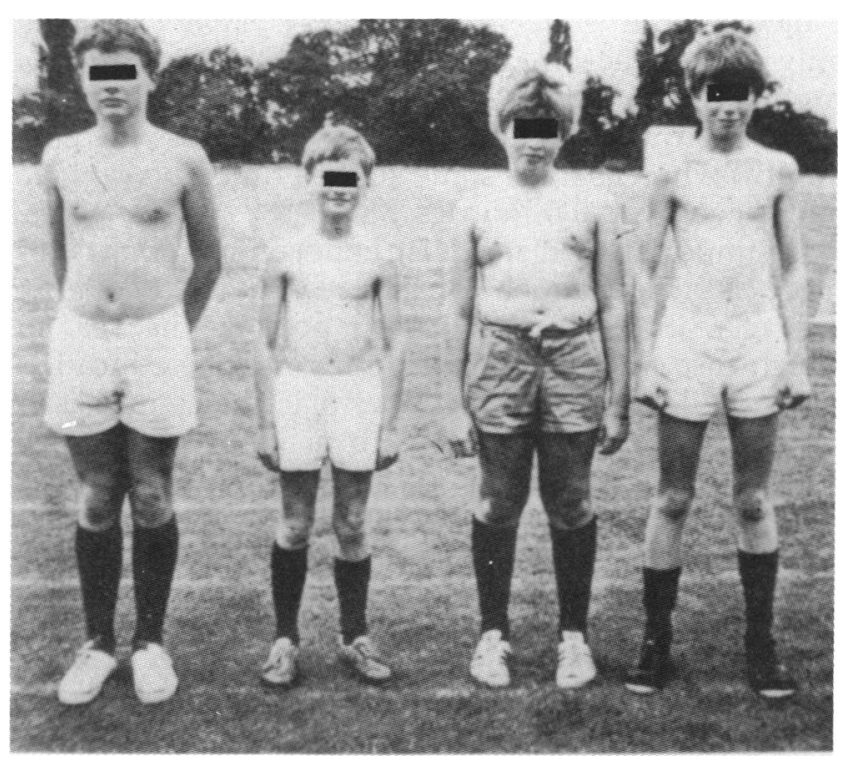

Figure 2. Difference in height and weight in 11-year-old boys. At puberty this discrepancy increases

\section{Lack of fitness}

\section{Gymnastics/trampolining}

General physical fitness of the gymnast/trampolinist did not seem to be a major factor in causing accidents. However, two trampolinists had become fatigued, one accident occurred because the participant was out of practice and another may be attributed to insufficient warm-up. One gymnast was reported as being tired, and a soldier had not done a certain exercise for a considerable period of time.

\section{Rugby}

Nine rugby players were injured because they were not fit enough. Four claimed that they were not generally fit to be playing any kind of sport. Five players were injured in the first game of the season. A player's failure to warm-up gave rise to an accident in the first moment of the game.

Three players were injured because they had not received sufficient specific training, i.e. fit for the particular task.

\section{Equipment failure}

This was rare. One or two accidents in trampolining can be attributed to this and one in horse-riding.

\section{Introduction of new equipment or new laws}

\section{Gymnastics/trampolining}

The trampette is a powerful piece of equipment enabling uncontrolled height to be achieved and was responsible for 15 of the accidents (Figure 3 ).

The trampoline was introduced into this country in 1949. Initially all the accidents took place on unsupervised trampolines, but latterly the dangers of using equipment that projects one $6 \mathrm{~m}$ up have been realised and with correct supervision/coaching serious accidents have been virtually eliminated.

Rugby

The changes in the ruck and maul laws were introduced in 1970 and have resulted in a dramatic increase in the number of injuries sustained, peaking in 1980 with nine tackle/ruck and maul incidents (Figure 4).

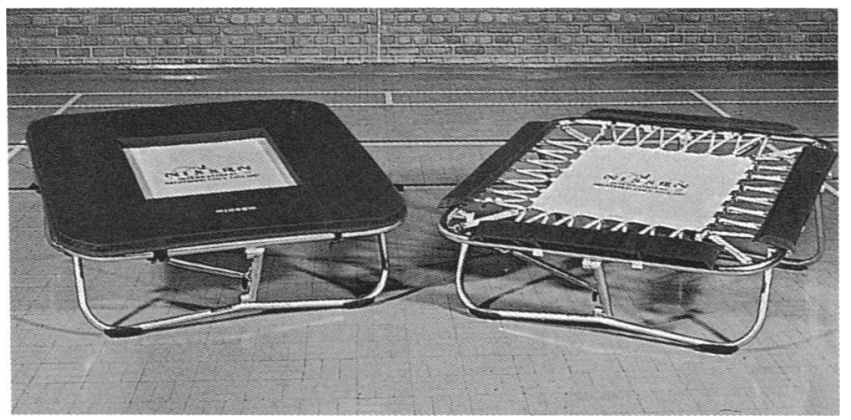

Figure 3. Two different types of trampette - a powerful piece of equipment that superseded the springboard 


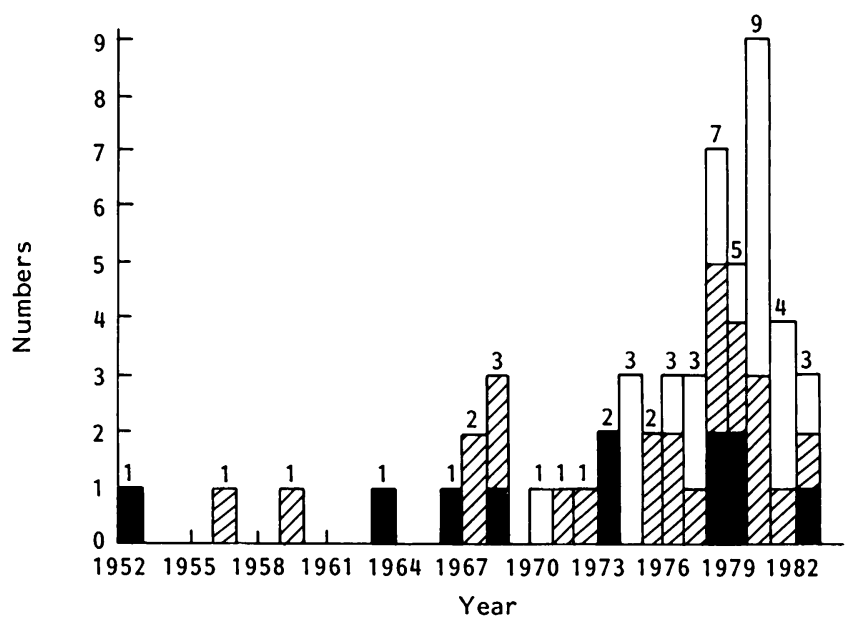

Figure 4. Numbers of injuries occurring in set scrums ( $\square$ ), tackles $(\square)$, and rucks and mauls $(\square)$ in rugby union football by year (figures at top of each column indicate total number of such injuries each year)

\section{Compulsion}

Compulsion in schools, prisons or the armed forces, where athletes are compelled to do the sport, imposes strains. Thirteen of the patients were in the forces, three in the police force at one particular college, and one was in prison (Figure 5).

\section{Discussion}

The retrieval of information was difficult. Doctors are concerned with treating the patient's injuries and not how the injuries occurred; as a consequence it is frequently difficult to discover that a sporting accident has actually taken place. For example there was confusion between a horse-riding accident and vaulting over a gymnastic horse. The causes of many sporting accidents went unrecorded when research was carried out at the spinal centre. Approximately 8500 patients have been treated at the NSIC, $25 \%$ of traumatic injuries were caused by falls. The relative increase in the number of sporting injuries may reflect the greater amount of time available for leisure

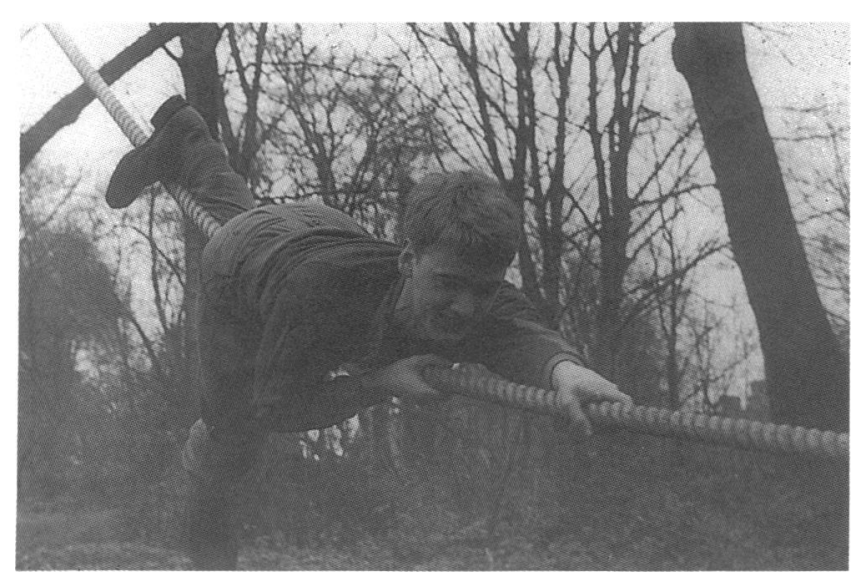

Figure 5. Injury occurs in the armed forces when gymnastic training is used to foster independence activities and the ever bigger role sport is playing in our daily lives. As society has become more affluent riding and snow sports accidents have increased accordingly.

The sex difference was striking. While clearly there are women who play rugby, it is on a touch basis and the numbers are small. Even in the sports where many women participate, e.g. gymnastics and trampolining, more men are injured, either as a result of more aggressive behaviour, a higher degree of competitiveness or possibly because the disciplines are different - women's gymnastics emphasizes agility, grace and dance, whereas men's is more dependent on strength. This is supported by statistics in other sports - of 150 patients admitted to NSIC as a result of diving accidents, 142 were male ${ }^{8}$. Only in horse-riding do injuries to women predominate, reflecting the large number of women who ride. In other soft tissue injuries there is little difference between men and women'. However, boys over 14 years of age are three times more commonly injured than girls of the same age ${ }^{10}$, which would seem to support our thesis about the preponderance of severe injuries among males.

Although one or two elderly people sustained injuries as a result of horse-riding, the majority of patients were young inexperienced people, and in common with road traffic accidents, lacking judgment and not always responding appropriately to guidance.

Despite the fact that during sport, particularly soccer and rugby, falls, kicks or blows are common they rarely give rise to thoracic or lumbar spinal cord injury. The cervical spine, however, is especially at risk of injury as is shown in the figures - 121 of the cases were cervical injuries. It is not as strong as the thoracic and lumbar spines. The cervical cord is injured (in sporting activities where the head leads, for example rugby, gymnastics and horse-riding), when force is transmitted through the skull to the cervical vertebrae. In diving, unless the head strikes the bottom, the spine is not injured. From an estimated four to five million soccer players we have only seen three broken necks (one resulting from a rugby-type tackle, one from a slip, driving the head into the ground, and one from diving across the goal mouth) whereas from some 400000 rugby players we have seen over 100 injuries.

It is important to distinguish between sport that takes place as a recreational or leisure activity (Figure 6), e.g. recreational diving into a pool or the sea, in which case more attention to preventative education is required, and sport that takes place in a supervised capacity - at school, in a club or competition. The gymnasium is a dangerous place. Six of the 16 trampoline and five of 38 gymnastic accidents occurred in an unsupervised gymnasium. The unsupervised use of equipment is hazardous - a trampoline can project the athlete 6-9 $\mathrm{m}$ into the air.

Supervision falls into two categories. General supervision ensures that dangerous equipment such as springboards and boxes are kept locked up and that gymnasts do not use the equipment on their own. Specific supervision ensures that dangerous exercises do not take place simultaneously, that 


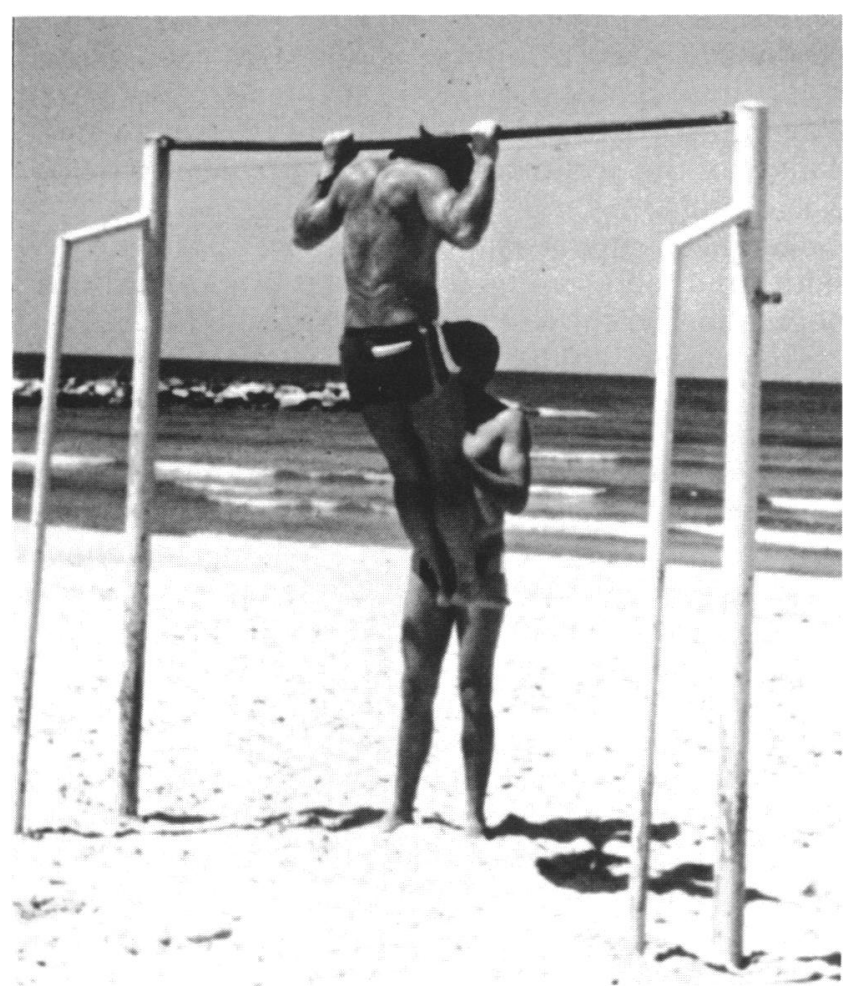

Figure 6. Apparatus provided in public areas is a trap. An accident waiting to happen

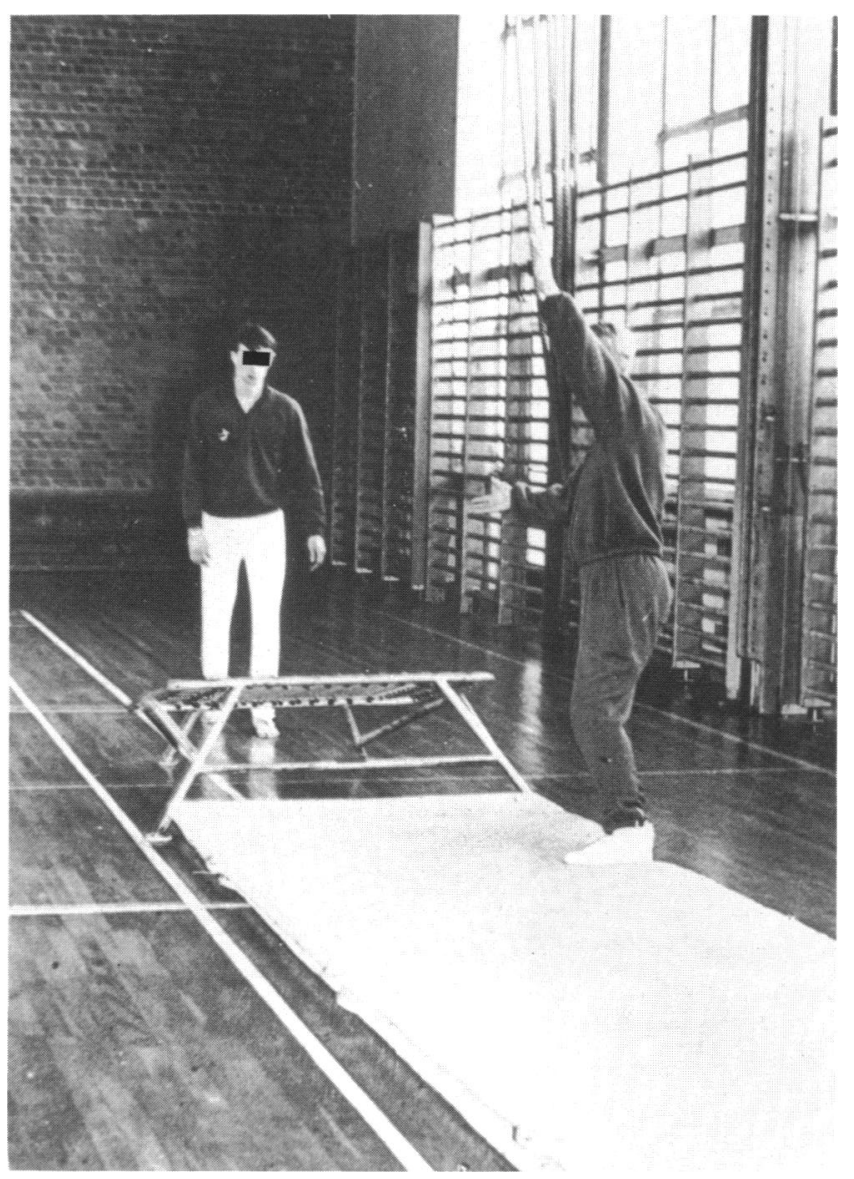

Figure 7. A scene of an accident. Could the catcher adequately fulfil the role required of him? instructors are competent and qualified to teach and aware of the standard of the gymnast so that overambitious moves are not attempted (Figure 7). The problem exists in rugby because inadequate, or indeed no, refereeing in rugby can result in injuries. Junior players are often unskilled and lack understanding of correct and safe techniques making up in hard contact and enthusiasm what they lack in skill. At this level a properly trained referee is often not available and this duty may be carried out by an unfit team member or a friend who has only a scanty knowledge of the laws. Illegal and unfortunate events may occur and tempers may be lost - the maul and rucks continue far too long and infringements take place through ignorance.

An important concept that emerged was that of a mismatch between the skills of the sportsman and the task attempted; a relatively straightforward task could prove difficult or dangerous for an inexperienced sportsman. This is particularly common in gymnastics and trampolining where athletes can be pressed by the coach to undertake advanced manoeuvres. Greater skill does not afford protection when the expert or the teacher attempts a new exercise he becomes a beginner again. In rugby the mismatch was of particular concern in the front row of the scrum where schoolboys with neither the strength nor skill were playing against adults. As a result the scrum easily collapsed causing injuries. This problem has been addressed as a result of this research - changes in the law have been introduced and injuries thus reduced.

In horse-riding accidents occurred when tasks were attempted that were not appropriate to the skills of the rider (Figure 8).

Activities that can be carried out safely in practice, when no stress or strain is involved, can become difficult when the gymnast, athlete or player competes and in competitive sports involving bodily contact, e.g. rugby, emotion and desire to win can override a skilled performance. It is striking that although a large number of players participate in

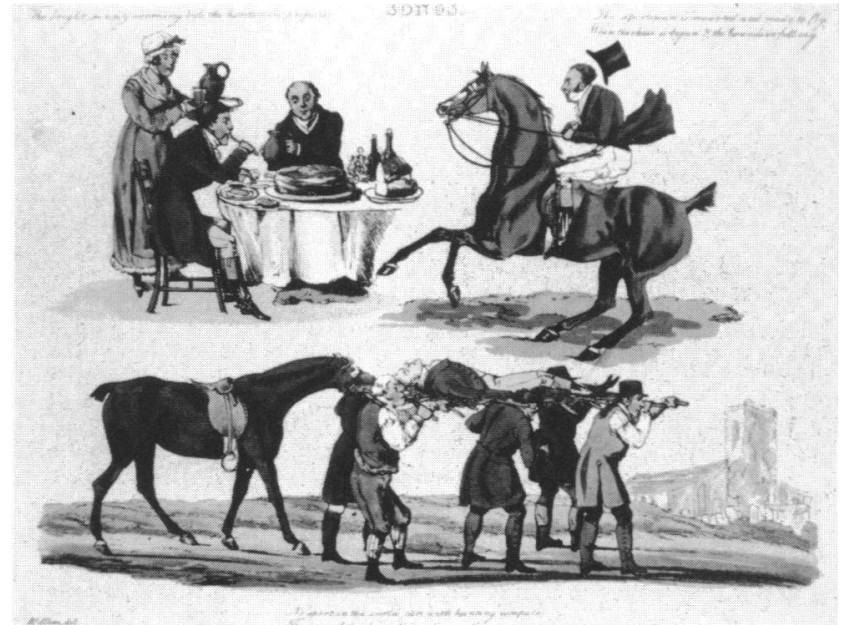

Figure 8. Alcohol can impair judgment and, combined with the excitement produced by the occasion, can cause an accident 
school games the vast majority of spinal injuries occurred in inter-school games, or against the 'old boys'.

A potent source of injury is when new equipment/ rules are introduced to a sport and render even the experienced participant a beginner. When the trampoline was first introduced it was regarded as a fun toy, and was used indiscriminately and without supervision (Figure 9). Once the dangers were appreciated virtually all trampolining accidents were eliminated. The trampette, introduced in the early 1970s, also allows uncontrolled height. It is possible to over-rotate or leave the trampette at an angle causing the gymnast to miss the mat altogether, and catchers seem ineffective, i.e. it is impossible to catch a $70-76 \mathrm{~kg}-\mathrm{man}$ coming off a trampette at speed. Fifteen of the injured had used the trampette.

Rugby should be primarily a running and passing game, and before 1970 when a player was tackled he had to release the ball but in an effort to make the game faster, the tackle law was changed allowing the player to hold on. As a result large and powerful men fought and wrestled for the ball, and pushed the

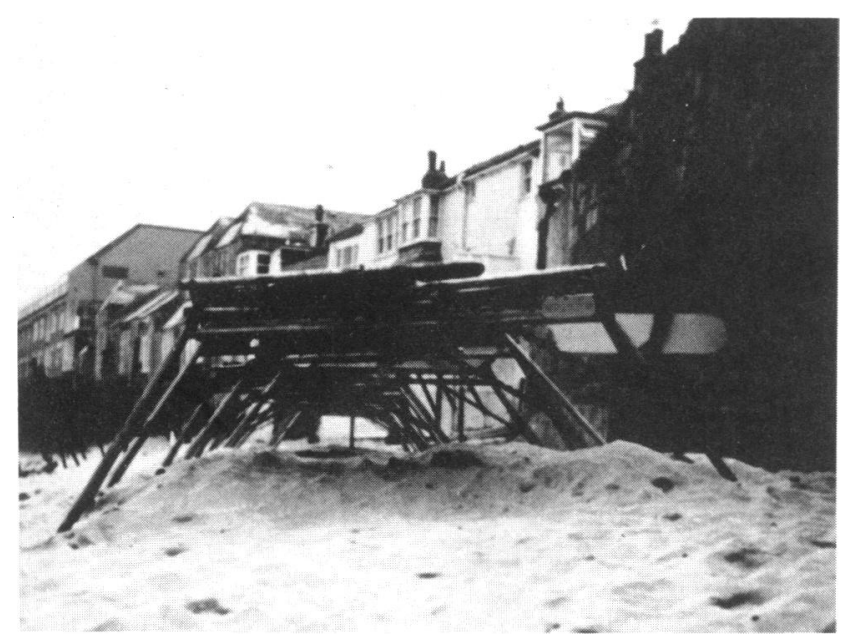

Figure 9. Trampoline in a play park. Note ageing, rusting equipment and proximity to wall. Surprisingly there is no record of accidents in this area, maybe because the children do not bounce up high ball-carrying player into the ground, producing a new mechanism of injury. There were no ruck and maul injuries before 1970, they increased to a maximum of six a year, and only decreased when the danger of this technique was recognized and the law was changed.

The increasing availability of snow sports such as skiing and tobogganing to a greater proportion of the population has also led to more spinal injuries.

There is a myth that no sport is worth doing unless it involves paying a price and many sportsmen think this is acceptable when they are young, and unaware of the danger. The analyses of these injuries show that the cervical spine is particularly vulnerable.

There are common factors: young impetuous untrained people using advanced equipment; inadequate supervision; and a motivation to attempt tasks beyond their abilities.

The concept of mismatch between the abilities of the performer and the task attempted should be analysed in all sport so that those responsible can ask the questions: Is the sport adequately supervised? Has the participant been trained? Is he capable of the task set him?

\section{References}

1 Silver JR. Injuries of the spine sustained in rugby. $\mathrm{Br} \mathrm{Med} J$ 1984; 288: 37-43.

2 Silver JR, Gill S. Injuries of the spine sustained during rugby. Sports Med 1988; 5: 328-44.

3 Silver JR, Silver DD, Godfrey JJ. Injuries of the spine sustained during gymnastic activities. $\mathrm{Br}$ Med $J$ 1986; 293: 861-3.

4 Silver JR, Silver DD, Godfrey JJ. Trampolining injuries of the spine. Injury 1986; 17: 117-24.

5 Silver JR, Lloyd Parry JM. Hazards of horse-riding as a popular sport. Br J Sports Med 1991; 25: 105-10.

6 Roaf R. A study of the mechanics of spinal injuries. J Bone Joint Surg [Br] 1960; 42-B: 810-23.

7 Bauze RJ, Ardran GM. Experimental production of forward dislocation in the human cervical spine. J Bone Joint Surg [Br] 1978; 60-B: 239-45.

8 Frankel HL, Montero FA, Penny PT. Spinal cord injury due to diving. Paraplegia 1980; 18: 118-22.

9 Whiteside PA. Men's and women's injuries in comparable sports. Physician and Sportsmedicine 1980; 8: 130-40.

10 Watson AWS. Sports injuries during one academic year in 6799 Irish school children. Am J Sports Med 1984; 12: 65-71. 